\title{
TITLE
}

\section{Predicting Response after Infliximab Salvage in Acute Severe Ulcerative Colitis}

\begin{abstract}
Objectives: Acute severe ulcerative colitis (ASUC) is a medical emergency requiring prompt therapeutic intervention. Although Infliximab has been used as salvage therapy for over 15 years, clinical predictors of treatment success are lacking. We performed a retrospective analysis to identify factors that predict colectomy and may guide dose intensification.
\end{abstract}

Methods: 54 hospitalized patients received infliximab for ASUC at 7 Australian centres (April 2014-May 2015). Follow-up was over 12 months. The data was primarily analysed for predictors of colectomy. Accelerated (AI) versus standard (SI) infliximab induction strategies were also compared.

Results: Of 54 patients identified, the overall colectomy rate was $15.38 \%(8 / 52)$ at 3 months and 26.92\% (14/52) at 12 months. Two patients were lost to followup. There was a numerically higher colectomy rate in those treated with Al compared to SI $(p=0.3)$; however those treated with Al had more severe biochemical disease. A CRP/Albumin ratio cut-off of 0.37 post-commencement of infliximab and prior to discharge was a significant predictor of colectomy with an area under receiver operating curve of 0.73 . Pretreatment CRP and albumin levels were not predictive of colectomy. A Mayo Endoscopic Score of 2 had a 94\% PPV for avoidance of colectomy following infliximab salvage.

Conclusions: The baseline Mayo Endoscopic Score and the CRP/Albumin ratio following infliximab salvage are significant predictors of treatment response for

This is the author manuscript accepted for publication and has undergone full peer review but has not been through the copyediting, typesetting, pagination and proofreading process, which may lead to differences between this version and the Version of Record. Please cite this article as doi: $10.1111 /$ jgh.14072

This article is protected by copyright. All rights reserved. 
ASUC and identify patients at high risk of colectomy. Whether this risk can be mitigated using infliximab dose intensification requires prospective evaluation before the CRP/Albumin ratio can be integrated into ASUC management algorithms.

Keywords: Ulcerative Colitis; Infliximab; Colectomy.

\begin{abstract}
Abbreviations
AUROC, Area Under the Receiver Operating Curve; Al, Accelerated Induction; ASUC, Acute Severe Ulcerative Colitis; CRP, C-reactive protein; IBD, Inflammatory Bowel Disease; MES, Mayo Endoscopic Score; NPV, Negative Predictive Value; PPV, Positive Predictive Value; Q1, Quartile 1; Q3, Quartile 3; SI, Standard Induction; TNF, Tumour Necrosis Factor; UCEIS, Ulcerative Colitis Endoscopic Index of Severity.
\end{abstract}

\title{
What does this paper add to the literature?
}

Infliximab is effective as salvage therapy for corticosteroid refractory acute severe ulcerative colitis; however assessment of response following the initiation of Infliximab is ill-defined. Here, we demonstrate that the Mayo Endoscopic Score and CRP/Albumin ratio following the commencement of infliximab can predict treatment response and identifies patients at high risk of colectomy. 


\section{INTRODUCTION}

Acute Severe Ulcerative Colitis (ASUC) is a potentially life-threatening condition which results in emergency colectomy in up to $30 \%$ of patients within three months of presentation.(1) One-third of patients do not respond to first-line corticosteroid therapy.(1) Infliximab and Cyclosporine have demonstrated equivalent efficacy as medical therapies for patients who fail to respond to corticosteroids; however, more than half of patients fail to respond to either drug.(2-4)

The standard induction schedule for infliximab comprising of 3 doses at $5 \mathrm{mg} / \mathrm{kg}$ given at Week 0,2 and 6 has been derived from studies of Crohn's disease and Rheumatoid arthritis. $(5,6)$ However, these diseases differ in their biology and inflammatory disease burden from patients with ASUC.

A retrospective study by Gibson and colleagues found that an accelerated infliximab induction schedule within four weeks reduced early colectomy rates at one month compared to standard induction treatment over six weeks.(7) Such an approach has been supported by recent findings of increased infliximab drug clearance in ASUC and new mechanisms of loss of response due to faecal drug loss; $(8,9)$ however, identifying which patients are most likely to benefit from an accelerated strategy is unknown.

Previous studies in ASUC have focused on predictors of response to corticosteroid therapy such as the Travis (Oxford) criteria(10) and more recently the use of CRP/Albumin ratio.(11) The Ho index has been applied to predict colectomy prior to treatment with Cyclosporine.(12) There have been few studies which have specifically focused on predictors of response to infliximab salvage therapy in ASUC. We performed this study to identify clinical, endoscopic and biochemical markers of treatment response and failure; and to explore the impact of accelerated infliximab dosing compared with standard dosing in our cohort. 


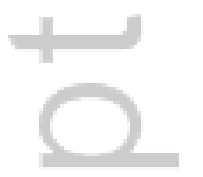




\section{MATERIALS AND METHODS}

\section{Study population}

A retrospective cohort study of 54 consecutive patients admitted to seven Australian tertiary hospitals between April 2014 and May 2015 was undertaken. All patients had steroid refractory ASUC as defined by the Truelove and Witt's(13) and Oxford criteria.(10) All patients had access to three doses of Infliximab $5 \mathrm{mg} / \mathrm{kg}$ under the Pharmaceutical Benefits Scheme of Australia. The standard Infliximab induction strategy utilized was $5 \mathrm{mg} / \mathrm{kg}$ at Week 0, 2 and $6(\mathrm{SI})$; however, accelerated induction (Al) whereby the second and third doses (both at $5 \mathrm{mg} / \mathrm{kg}$ ) were given ahead of schedule was individually determined at the discretion of the treating clinician based on: (i) a lack of adequate response to the first dose of infliximab; or (ii) an initial response followed by deterioration in symptoms such as stool frequency or rectal bleeding; or (iii) rise in inflammatory markers. Following successful induction, patients naïve to thiopurines were maintained on a combination of mesalazine and a thiopurine, whereas those experienced to thiopurines were maintained on infliximab. This study was approved by the Austin Health Research Ethics Committee, St Vincent's Hospital Research Ethics Committee, Alfred Health Research Ethics Committee, Eastern Health Research Ethics Committee, Melbourne Health Research Ethics Committee, Monash Health Research Ethics Committee and Royal Brisbane and Women's Hospital Ethics Committee.

\section{Statistical considerations}

Descriptive statistics were used to describe the study cohort and results reported as median (Q1-Q3) for continuous data and \%(N) for categorical data. Bi-variate analysis was used to evaluate differences between study groups ( $\mathrm{Al}$ vs $\mathrm{SI}$ ). Fisher's exact or Chi-square tests were used for categorical data and Wilcoxon Rank-Sum test for continuous data. Continuous data were tested for normality using the Shapiro-Wilk test. Logistic regression and sensitivity analysis (using senspec 
command in Stata) were used to determine the optimum CRP/Albumin ratio to predict the risk of colectomy alone and the composite of colectomy and early unplanned readmission for further salvage (within 6 weeks of initial infliximab salvage therapy). Data was analysed using a complete case approach. Comparison between patients who completed the follow-up and those who did not was performed to eliminate selection bias. All analyses were performed using Stata15 (Stata Statistical Software: Release 15. College Station, TX: StataCorp LLC); SPSS Version 22 (IBM SPSS Statistics for Windows, Version 22.0. Armonk, NY: IBM Corp) and $p<0.05$ was considered statistically significant.

\section{RESULTS}

\section{Demographics}

Fifty-four patients with ASUC were identified across seven institutions. 2 patients were lost to follow-up at 3 and 12 months. In our cohort, 35.2\% (19/54) were female and the median age was 33.2 years (Q1-Q3 27.4-44.7). Twenty percent (11/54) had a new diagnosis of UC and the median disease duration was 2.5 years (Q1-Q3 1.46.4). With respect to therapy at time of admission, $44.4 \%(24 / 54)$ were on oral steroids, $64.8 \%$ (35/54) were on oral aminosalicylates, 40.7\% (22/54) were on a thiopurine and $7.4 \%$ (4/54) were on methotrexate. No patients were on Infliximab prior to induction therapy. The median duration of IV steroids prior to initiating infliximab salvage was 4 days (Q1-Q3 3.0-6.0).

\section{Colectomy}

When accounting for the 2 patients who were lost to follow-up the overall colectomy rate was $15.4 \%(8 / 52)$ at 3 months and 26.9\% (14/52) at 12 months. The median time to colectomy was 55 days (Q1-Q3 26-131). Two patients underwent an emergency colectomy (within the same admission) after a single dose of infliximab. The remaining 12 patients underwent elective colectomy (following discharge). 


\section{Factors associated with colectomy}

Factors associated with colectomy are indicated in Table 1

\section{Clinical Factors}

No significant associations were observed between colectomy and age, disease duration or medication use. There was no significant difference in the duration of IV steroids prior to commencing Infliximab between those with colectomy (4.0 days (Q1-Q3 3.0-5.0) versus no colectomy (5.0 days (Q1-Q3 4.0-6.0); $p=0.43$ ).

\section{Endoscopic Factors}

There was a greater proportion of severe endoscopic disease (Mayo 3) in those who underwent colectomy compared to those who did not [90.9\% (10/11) vs 51.5\% (17/33); $p=0.03]$.

\section{Biochemical Factors}

Biochemistry was assessed at time of admission, time of induction, day 3 post induction and prior to discharge. Timing of discharge bloods are outlined in Table 2. Neither CRP, Albumin nor the CRP/Albumin ratio were significant predictors of colectomy at admission, induction or day 3. CRP or Albumin prior to discharge were also not significant predictors of colectomy. However, the CRP/Albumin ratio prior to discharge was predictive of future outcome. Those who came to colectomy had a significantly higher CRP/Albumin ratio prior to discharge than those who avoided colectomy at 12 months [0.7 (0.4-1.4) vs $0.3(0.1-0.7)$, respectively; $p=0.02$ ] (Table 1).

\section{Predictors of colectomy}


A Mayo Endoscopic Score (MES) of 2 predicted avoidance of colectomy within 12 months with $48 \%$ sensitivity, 91\% specificity, a positive predictive value (PPV) of $94 \%$ and negative predictive value (NPV) of 37\%. A MES of 3 predicted colectomy within 12 months with 91\% sensitivity, 48\% specificity, a PPV of $37 \%$ and NPV of $94 \%$.

A CRP/Albumin ratio of $>0.37$ at discharge predicted future colectomy with $80 \%$ sensitivity, 62\% specificity, a 42\% PPV and a NPV of 90\%; area under receiver operating curve (AUROC) of 0.73 (Figure 1). A cut-off of $<0.32$ has a $90 \%$ sensitivity, 55\% specificity, 41\% PPV and 94\% NPV for avoiding colectomy in the first 12 months.

\section{Accelerated vs Standard Infliximab Strategy}

Of the 54 patients who underwent salvage therapy, 51 patients formed the basis of this analysis as three patients had a single dose of infliximab (two of whom proceeded to colectomy). Seventy-three percent (37/51) underwent Standard induction (SI) and 27.5\% (14/51) had Accelerated induction. The comparison between both groups is shown in Table 3. SI was completed over 43.0 days (Q1-Q3 42.0-46.0) vs 25.0 days for $\mathrm{Al}(\mathrm{Q} 1-\mathrm{Q} 3$ 17.5-32.0); $\mathrm{p}<0.01$. Patients treated with $\mathrm{Al}$ had significantly higher CRP/Albumin ratio at time of induction [2.0 (Q1-Q3 0.6-5.2) vs 0.6 (Q1-Q3 0.2-1.7); $\mathrm{p}=0.02$ ]. Patients with Al had a longer length of stay compared to SI (12.5 days (Q1-Q3 10.8-16.0) vs 8.0 days (Q1-Q3 6.5-10.5); $\mathrm{p}<0.01$ ) and a higher proportion with Mayo 3 severe endoscopic disease activity (84.6\% $(11 / 13)$ vs $56.7 \%(17 / 30) ; p=0.10)$. The median time to colectomy was 104.0 days (Q1-Q3 35.0-231.0) in SI and 46.0 days (Q1-Q3 27.5-170.5) in Al; ( $p=0.53)$, demonstrated in Figure 2. Although there was no statistically significant difference in colectomy rate between the two induction strategies, there was a numerically higher rate in $\mathrm{Al}$ at 3 months (21.4\% (3/14) vs 8.6\% (3/35); p=0.33) and 12 months (35.7\% (5/14) vs 20.0\% (7/35); $p=0.29)$. 


\section{DISCUSSION}

Infliximab is an effective therapy in ASUC; however, despite its use in inflammatory bowel disease for over 15 years, the optimal dosing schedule in ASUC is still unknown. Factors determining which patients should be considered for salvage therapy for ASUC following corticosteroid failure are well established. In contrast, predictors of which patients do and do not respond to infliximab therapy following corticosteroid failure in ASUC are poorly understood. This study has demonstrated that accelerated induction was not superior to standard induction in our cohort; that the MES is a useful predictor of colectomy; and the CRP/Albumin ratio following the initiation of infliximab salvage therapy and prior to discharge for ASUC is predictive of colectomy.

A majority of clinicians favour accelerated or intensified Infliximab dose strategies in ASUC (14) with limited evidence to support this practice. Although Gibson and colleagues found an improved colectomy free survival with an accelerated induction schedule, the same was not found by Govani et al,(15) and Al Khoury et al,(16) with a high rate of treatment failure and post colectomy complications in those with accelerated dosing. One reason for this difference was that patients in the latter studies treated with accelerated dosing had biochemically more severe disease. We similarly found a numerically higher colectomy rate in those treated with accelerated induction possibly due to the presence of more severe biochemical and endoscopic disease; however, this lack of statistical difference likely relates to the limitation of our relatively small sample size. In our cohort CRP, Albumin and the CRP/Albumin ratio at admission, induction and Day 3 were not predictive of colectomy contrary to published literature, likely due to the fact that patients with more adverse biochemistry were treated with accelerated dosing which may have relatively improved the expected colectomy rate. Whilst formal costings were not performed in 
this study, length of stay is a surrogate marker. Accelerated induction patients had an increased length of stay with no improvement in colectomy free survival, raising the question of the cost effectiveness of more intensive medical therapy.

Emerging evidence suggests that there is a high burden of both circulating and mucosal TNF cytokine in ASUC which acts as a drug 'sink', and highly elevated levels are predictive of anti-TNF failure and colectomy. $(17,18)$ Infliximab clearance and the development of drug immunogenicity is more rapid in ASUC,(8) which likely relates to faecal drug loss (9) and occurs more commonly in patients with high CRP and low albumin levels.(19) Thus, patient selection is likely to be a key determinant of the optimal dosing schedule for infliximab. It has been proposed that patients with a CRP>50mg/L should receive a $10 \mathrm{mg} / \mathrm{kg}$ dose of infliximab as this group of patients are likely to have lower drug levels;(19) however, as to whether such an approach can overcome the pharmacokinetic barrier is yet to be proven. Flexible dosing with higher doses or accelerated infusion schedules tied to biochemical responses to treatment have entered clinical practice with limited evidence to support the effectiveness of such strategies (20).

Our data suggest that early post salvage biochemical parameters may more useful in providing practical prognostic information to clinicians and patients when assessing the success of infliximab induction than pre-treatment levels. Day 3 parameters were also not useful predictors, likely due to the influence of early intervention with accelerated dosing. The CRP/Albumin ratio prior to discharge with a cut-off of 0.37 and MES were highly predictive of the hard end-point of long term colectomy-free survival irrespective of whether a standard or accelerated induction strategy was adopted. This finding requires prospective validation as a predictor of colectomy in cohort studies. Whilst the Ulcerative Colitis Endoscopic Index Severity Score (UCEIS) is emerging as a strong predictor of outcome in ASUC (21), the MES is still of important value and was able to stratify those at a low risk of colectomy in our cohort. 
Assessment of response to infliximab in ASUC has yet to be clearly defined. There are no defined thresholds to guide what the initial dose of infliximab should be, what the ideal time is to determine clinical or biochemical response, and if and when further salvage doses should be given before primary failure can be judged and medical therapy aborted. Given that the CRP/Albumin ratio prior to discharge identifies patients at high risk of readmission for further salvage and colectomy, it may be clinically beneficial to integrate this biomarker into management algorithms to facilitate objective assessment of response to infliximab salvage, and guide decisions on when to apply dose intensification. We propose that patients who fail to achieve an adequate early improvement in the CRP/Albumin ratio to $<0.37$ following the commencement of infliximab salvage are high risk, who have poorly responded to initial infliximab treatment and who are in need of close monitoring, consideration of infliximab dose intensification or surgery.

This study has several limitations. Although the timing of discharge bloods is inherently variable, this is a pragmatic parameter that was found to have predictive value. This study may also have benefited from detailed post-induction clinical activity indices such as the Mayo Clinical Score, Lichtiger score or Rachmilewitz index to explore clinical response, however these data were not available to evaluate in this cohort. This study is also retrospective with a relatively small sample size. As such, a valid multivariate analysis could not be performed. Nonetheless this study was an exploratory evaluation which still permitted analysis of predictors of colectomy as the primary end-point of interest. Furthermore, whilst we did not find a statistically significant difference in colectomy rates between accelerated induction and standard induction, both groups had different baseline levels of biochemical inflammatory activity; however our sample size precluded adjustment for these covariates via propensity score weighting or regression analysis. Although this study was multicentric with potential differences in clinical management amongst the sites 
and assessment of endoscopic severity, this analysis captured the "real world" outcomes of 54 consecutive patients from seven separate institutions.

In keeping with recent expert consensus guidelines that endorse a treat-to-target strategy as the optimal approach to managing $\operatorname{IBD}(22)$ these data emphasize the importance of corroborating clinical improvement following infliximab salvage therapy with objective markers of inflammatory disease. The CRP/Albumin ratio appears to be a promising biomarker to determine response to infliximab therapy and its prognostic value requires prospective evaluation. Whether the risk of colectomy can be mitigated using infliximab dose intensification also warrants further exploration in controlled interventional studies. 


\section{REFERENCES:}

1. Kaplan GG, Seow CH, Ghosh S, Molodecky N, Rezaie A, Moran GW, et al. Decreasing colectomy rates for ulcerative colitis: a population-based time trend study. The American journal of gastroenterology. 2012;107(12):1879-87.

2. Laharie D, Bourreille A, Branche J, Allez M, Bouhnik Y, Filippi J, et al. Ciclosporin versus infliximab in patients with severe ulcerative colitis refractory to intravenous steroids: a parallel, open-label randomised controlled trial. Lancet. 2012;380(9857):1909-15.

3. Williams JG, Alam MF, Alrubaiy L, Arnott I, Clement C, Cohen D, et al. Infliximab versus ciclosporin for steroid-resistant acute severe ulcerative colitis (CONSTRUCT): a mixed methods, open-label, pragmatic randomised trial. The Lancet Gastroenterology \& Hepatology. 2016;1(1):15-24.

4. Narula N, Marshall JK, Colombel JF, Leontiadis GI, Williams JG, Muqtadir Z, et al. Systematic Review and Meta-Analysis: Infliximab or Cyclosporine as Rescue Therapy in Patients With Severe Ulcerative Colitis Refractory to Steroids. The American journal of gastroenterology. 2016.

5. Hanauer SB, Feagan BG, Lichtenstein GR, Mayer LF, Schreiber S, Colombel JF, et al. Maintenance infliximab for Crohn's disease: the ACCENT I randomised trial. Lancet. 2002;359(9317):1541-9.

6. Maini R, St Clair EW, Breedveld F, Furst D, Kalden J, Weisman M, et al. Infliximab (chimeric anti-tumour necrosis factor alpha monoclonal antibody) versus placebo in rheumatoid arthritis patients receiving concomitant methotrexate: a randomised phase III trial. ATTRACT Study Group. Lancet. 1999;354(9194):1932-9. 7. Gibson DJ, Heetun ZS, Redmond CE, Nanda KS, Keegan D, Byrne K, et al. An Accelerated Infliximab Induction Regimen Reduces the Need for Early Colectomy in Patients With Acute Severe Ulcerative Colitis. Clinical gastroenterology and hepatology : the official clinical practice journal of the American Gastroenterological Association. 2014. 
8. Kevans D, Murthy S, lacono A, Silverberg MS, Greenberg GR. Sa2031 Accelerated Clearance of Serum Infliximab During Induction Therapy for Acute Ulcerative Colitis is Associated With Treatment Failure. Gastroenterology.142(5):S384-S-5.

9. Brandse JF, van den Brink GR, Wildenberg ME, van der Kleij D, Rispens T, Jansen JM, et al. Loss of Infliximab Into Feces is Associated With Lack of Response to Therapy in Patients with Severe Ulcerative Colitis. LID - S0016-5085(15)00572-7 [pii] LID - 10.1053/j.gastro.2015.04.016 [doi]. 2015(1528-0012 (Electronic)).

10. Travis SP, Farrant JM, Ricketts C, Nolan DJ, Mortensen NM, Kettlewell MG, et al. Predicting outcome in severe ulcerative colitis. Gut. 1996;38(6):905-10.

11. Gibson D, Hartery K, Doherty J, Nolan J, Horgan G, Buckley M, et al. Su1813 CRP/Albumin Ratio: A Novel Predictor of Early Colectomy in Acute Severe Ulcerative Colitis. Gastroenterology.150(4):S560.

12. Aceituno M, Garcia-Planella E, Heredia C, Zabana Y, Feu F, Domenech E, et al. Steroid-refractory ulcerative colitis: predictive factors of response to cyclosporine and validation in an independent cohort. Inflammatory bowel diseases. 2008;14(3):347-52.

13. Truelove SC, Witts LJ. Cortisone in ulcerative colitis; final report on a therapeutic trial. British medical journal. 1955;2(4947):1041-8.

14. Herfarth HH, Rogler G, Higgins PD. Pushing the pedal to the metal: should we accelerate infliximab therapy for patients with severe ulcerative colitis? Clinical gastroenterology and hepatology : the official clinical practice journal of the American Gastroenterological Association. 2015;13(2):336-8.

15. Govani SM, Waljee AK, Stidham RW, Higgins P, Hardiman K. 516 Accelerated Dosing of Infliximab Prevents Colectomy Within 90 Days in Only Half of Patients With Severe Ulcerative Colitis. Gastroenterology.150(4):S106.

16. Al Khoury A, Chao Cy, Aruljothy A, Wyse J, Bessissow T. P495 Intensified infliximab rescue therapy for acute severe ulcerative colitis does not improve long term colectomy-free survival. Journal of Crohn's and Colitis. 2017;11(suppl_1):S330S1. 
17. Olsen T, Goll R, Cui G, Husebekk A, Vonen B, Birketvedt GS, et al. Tissue levels of tumor necrosis factor-alpha correlates with grade of inflammation in untreated ulcerative colitis. Scandinavian journal of gastroenterology. 2007;42(11):1312-20.

18. Matro R, Lin K, Velayos FS, Jain A, Kondragunta V, Singh S, et al. Tu1307 Using Serum Infliximab Drug and TNF Cytokine Concentration to Predict Clinical Outcome After High-Dose Infliximab in the Treatment of Severe Ulcerative Colitis: A Pilot Study. Gastroenterology. 2015;148(4):S-854.

19. Brandse JF, Mathot RA, van der Kleij D, Rispens T, Ashruf Y, Jansen JM, et al. Pharmacokinetic Features and Presence of Anti-drug Antibodies Associate With Response to Infliximab Induction Therapy in Patients with Moderate to Severe Ulcerative Colitis. Clinical gastroenterology and hepatology : the official clinical practice journal of the American Gastroenterological Association. 2015.

20. University of Michigan Severe Ulcerative Colitis Protocol2016 20/11/2016.

Available from: http://www.med.umich.edu/ibd/docs/severeucprotocol.pdf.

21. Corte C, Fernandopulle N, Catuneanu AM, Burger D, Cesarini M, White L, et al. Association between the ulcerative colitis endoscopic index of severity (UCEIS) and outcomes in acute severe ulcerative colitis. Journal of Crohn's \& colitis. 2015;9(5):376-81.

22. Peyrin-Biroulet L, Sandborn W, Sands BE, Reinisch W, Bemelman W, Bryant $\mathrm{RV}$, et al. Selecting Therapeutic Targets in Inflammatory Bowel Disease (STRIDE): Determining Therapeutic Goals for Treat-to-Target. The American journal of gastroenterology. 2015;110(9):1324-38. 


\section{TABLES}

Table 1. Comparison of patients who underwent colectomy vs those who were colectomy free at 12 months

Note: Continuous data reported as median (Q1-Q3) and analysed using Wilcoxon rank-sum test; categorical data reported $\mathrm{n}(\%)$ and analysed using Fisher's exact test

\begin{tabular}{|c|c|c|c|}
\hline Median and Q1-Q3 & $\begin{array}{c}\text { No colectomy } \\
\mathrm{N}=38\end{array}$ & $\begin{array}{c}\text { Colectomy } \\
\mathrm{N}=14\end{array}$ & $P$ value \\
\hline $\begin{array}{c}\text { Gender } \\
\text { Female } \mathrm{n}(\%)\end{array}$ & $16(42.1)$ & $3(21.4)$ & 0.44 \\
\hline Age (years) & $32.7(27.1-42.9)$ & $40.9(26.9-57.4)$ & 0.21 \\
\hline Disease duration (years) & $2.50(1.4-6.4)$ & $2.48(0.8-10.7)$ & 0.88 \\
\hline $\begin{array}{l}\text { Duration of IV steroids prior to } \\
\text { initiating Infliximab (days) }\end{array}$ & $5.0(4.0-6.0)$ & $4.0(3.0-5.5)$ & 0.43 \\
\hline $\begin{array}{l}\text { Medications on admission } \mathrm{n}(\%) \\
\text {-Oral Steroids } \\
\text {-Mesalazine } \\
\text {-Immunomodulator (Thiopurine or } \\
\text { Methotrexate) }\end{array}$ & $\begin{array}{l}18(47.4) \\
26(68.4) \\
17(44.7)\end{array}$ & $\begin{array}{l}5(35.7) \\
8(57.1) \\
8(57.1)\end{array}$ & $\begin{array}{l}0.54 \\
0.52 \\
0.54\end{array}$ \\
\hline $\begin{array}{c}\text { CRP mg/L } \\
\text {-admission } \\
\text {-at induction } \\
\text {-Day } 3 \text { post Infliximab } \\
\text { - prior to discharge* }\end{array}$ & $\begin{array}{l}38(19.0-82.0) \\
17.0(7.5-46.4) \\
8.5(2.8-36.0) \\
7.00(2.8-21.7)\end{array}$ & $\begin{array}{c}54.0(31.0-170.0) \\
33.0(10.3-55.0) \\
12.3(10.0-19.0) \\
17.00(8.00-30.0)\end{array}$ & $\begin{array}{l}0.10 \\
0.38 \\
0.24 \\
0.11\end{array}$ \\
\hline $\begin{array}{c}\text { Albumin g/L } \\
\text {-admission } \\
\text {-at induction } \\
\text {-Day } 3 \text { post Infliximab } \\
\text { - prior to discharge * }\end{array}$ & $\begin{array}{l}31.0(27.0-35.0) \\
26.0(22.0-31.0) \\
26.0(22.5-30.5) \\
28.0(24.0-34.0)\end{array}$ & $\begin{array}{l}31.0(29.0-34.0) \\
23.0(20.0-29.0) \\
25.5(22.0-30.5) \\
27.0(22.0-29.0)\end{array}$ & $\begin{array}{l}0.96 \\
0.29 \\
0.98 \\
0.30\end{array}$ \\
\hline $\begin{array}{l}\text { CRP/Albumin ratio } \\
\text {-admission } \\
\text {-at induction } \\
\text {-Day } 3 \text { post Infliximab } \\
\text {-prior to discharge* }\end{array}$ & $\begin{array}{l}1.1(0.5-3.5) \\
0.6(0.3-1.9) \\
0.3(0.1-1.1) \\
0.3(0.1-0.7)\end{array}$ & $\begin{array}{l}2.0(0.9-4.3) \\
1.4(0.6-1.9) \\
0.5(0.4-0.7) \\
0.7(0.4-1.4)\end{array}$ & $\begin{array}{l}0.17 \\
0.45 \\
0.17 \\
0.02\end{array}$ \\
\hline $\begin{array}{c}\text { Mayo Endoscopic score } \\
-2 \\
-3\end{array}$ & $\begin{array}{l}16 / 33 \\
17 / 33\end{array}$ & $\begin{array}{c}1 / 11 \\
10 / 11\end{array}$ & 0.03 \\
\hline
\end{tabular}

*Excluding 2 patients who underwent colectomy prior to discharge and 1 patient who suffered pancreatitis following inpatient use of thiopurine 
Tables 2. Timing of discharge bloods

Analysis based on 36 patients with available CRP and Albumin levels

\begin{tabular}{|l|c|c|c|}
\hline \multicolumn{1}{|c|}{ Median and Q1-Q3 } & $\begin{array}{c}\text { No colectomy } \\
\mathrm{n}=26\end{array}$ & $\begin{array}{c}\text { Colectomy } \\
\mathrm{n}=10\end{array}$ & P value \\
\hline $\begin{array}{l}\text { Time to discharge bloods } \\
\text { following last Infliximab dose } \\
\text { (days) }\end{array}$ & $3.0(1.0-5.0)$ & $3.0(2.0-4.0)$ & 0.80 \\
\hline $\begin{array}{l}\text { Number of Infliximab infusions } \\
\text { prior to discharge bloods taken }\end{array}$ & & & \\
$\mathrm{n}(\%)$ & $20 / 26(76.9)$ & $7 / 10(70.0)$ & \\
-1 infusion & $4 / 26(15.4)$ & $3 / 10(30.0)$ & 0.69 \\
-2 infusions & $2 / 26(7.7)$ & $0 / 10(0.0)$ & 1.00 \\
-3 infusions & & & \\
\hline
\end{tabular}

This article is protected by copyright. All rights reserved. 
Table 3. Comparison of Standard versus Accelerated Induction Note: Continuous data reported as median (Q1-Q3) and analysed using Wilcoxon rank-sum test; categorical data reported $\mathrm{n}(\%)$ and analysed using Fisher's exact test

\begin{tabular}{|l|c|c|c|}
\hline \multicolumn{1}{|c|}{ Median and Q1-Q3 } & $\begin{array}{c}\text { Standard induction } \\
\mathrm{n}=37\end{array}$ & $\begin{array}{c}\text { Accelerated induction } \\
\mathrm{n}=14\end{array}$ & P value \\
\hline Gender & $14(37.8)$ & $5(35.7)$ & 1.00 \\
Female, $\mathrm{n}(\%)$ & $32.61(26.7-44.4)$ & $37.33(26.7-46.6)$ & 0.54 \\
\hline Age (years) & $2.50(1.4-6.4)$ & $2.68(1.6-7.2)$ & 0.83 \\
\hline Disease duration (years) & & & \\
\hline Medications on admission, & & $7(50.0)$ & 0.75 \\
$\mathrm{n}(\%)$ & $15(40.5)$ & $7(50.0)$ & 0.20 \\
-Oral Steroids & $26(70.3)$ & $5(35.7)$ & 0.36 \\
-Mesalazine & $19(51.4)$ & $4.0(3.0-5.0)$ & 0.28 \\
-Immunomodulator & $5.0(3.5-6.0)$ & & \\
\hline IV steroid duration & & & 0.11 \\
\hline CRP (mg/L) & $35.0(17.5-69.5)$ & $63.0(20.0-167.5)$ & 0.15 \\
-admission & $17.0(4.9-42.0)$ & $35.0(10.3-79.0)$ & 0.15 \\
-at induction & $6.5(1.9-15.0)$ & $10.00(8.1-43.0)$ & 0.12 \\
-Day 3 post Infliximab & $7.5(2.8-18.5)$ & $17.00(6.5-40.5)$ & \\
-prior to discharge & & & 0.63 \\
\hline Albumin (g/L) & $31.0(27.0-35.0)$ & $30.5(23.0-35.8)$ & 0.21 \\
-admission & $26.0(22.0-30.8)$ & $23.0(18.0-30.5)$ & 0.66 \\
-at induction & $25.5(21.8-30.3)$ & $25.0(20.3-30.8)$ & 0.60 \\
-Day 3 post infliximab & $28.0(26.0-32.0)$ & $26.5(23.3-34.0)$ & \\
-prior to discharge & & & \\
\hline CRP Albumin ratio & $1.0(0.6-2.7)$ & $2.5(0.6-5.7)$ & 0.15 \\
-admission & $0.6(0.2-1.7)$ & $2.0(0.6-5.2)$ & 0.02 \\
-at induction & $0.3(0.1-0.6)$ & $0.4(0.3-1.7)$ & 0.33 \\
-Day 3 post infliximab & $0.3(0.1-0.7)$ & $0.5(0.3-1.3)$ & 0.38 \\
-prior to discharge & & & \\
\hline Mayo Endoscopic score & & $2 / 13(15.4)$ & 0.10 \\
n(\%) & $13 / 30(43.3)$ & $11 / 13(84.6)$ & \\
-2 & $17 / 30(56.7)$ & $4.0(3.0-5.8)$ & 0.45 \\
-3 & $5.0(3.5-6.0)$ & & \\
\hline Time to induction (days) & & & \\
& & & \\
\hline
\end{tabular}




\begin{tabular}{|l|c|c|c|}
\hline Time to second dose & $14.0(14.0-16.0)$ & $4.5(3.0-8.0)$ & $<0.01$ \\
\hline $\begin{array}{l}\text { Duration of induction } \\
\text { (days) }\end{array}$ & $43.0(42.0-46.0)$ & $25.0(17.5-32.0)$ & $<0.01$ \\
\hline Length of stay (days) & $8.0(6.5-10.5)$ & $12.5(10.8-16.0)$ & $<0.01$ \\
\hline $\begin{array}{l}\text { Colectomy rate } \\
-3 \text { months }\end{array}$ & $3 / 35(8.6)$ & $3 / 14(21.4)$ & 0.33 \\
-12 months & $7 / 35(20.0)$ & $5 / 14(35.7)$ & 0.29 \\
\hline $\begin{array}{l}\text { Median time to colectomy } \\
\text { (days) }\end{array}$ & $104.0(35.0-231.0)$ & $46.0(27.5-170.5)$ & 0.53 \\
\hline
\end{tabular}

FIGURE LEGENDS

Figure 1. Area under Receiver Operating Curve (ROC) for CRP/Albumin ratio of 0.37 prior to discharge to predict colectomy

Figure 2. Kaplan Meier curve:

Standard vs Accelerated Induction - Time to Colectomy ( $p=0.29$ at 12 months) 
Survival Functions

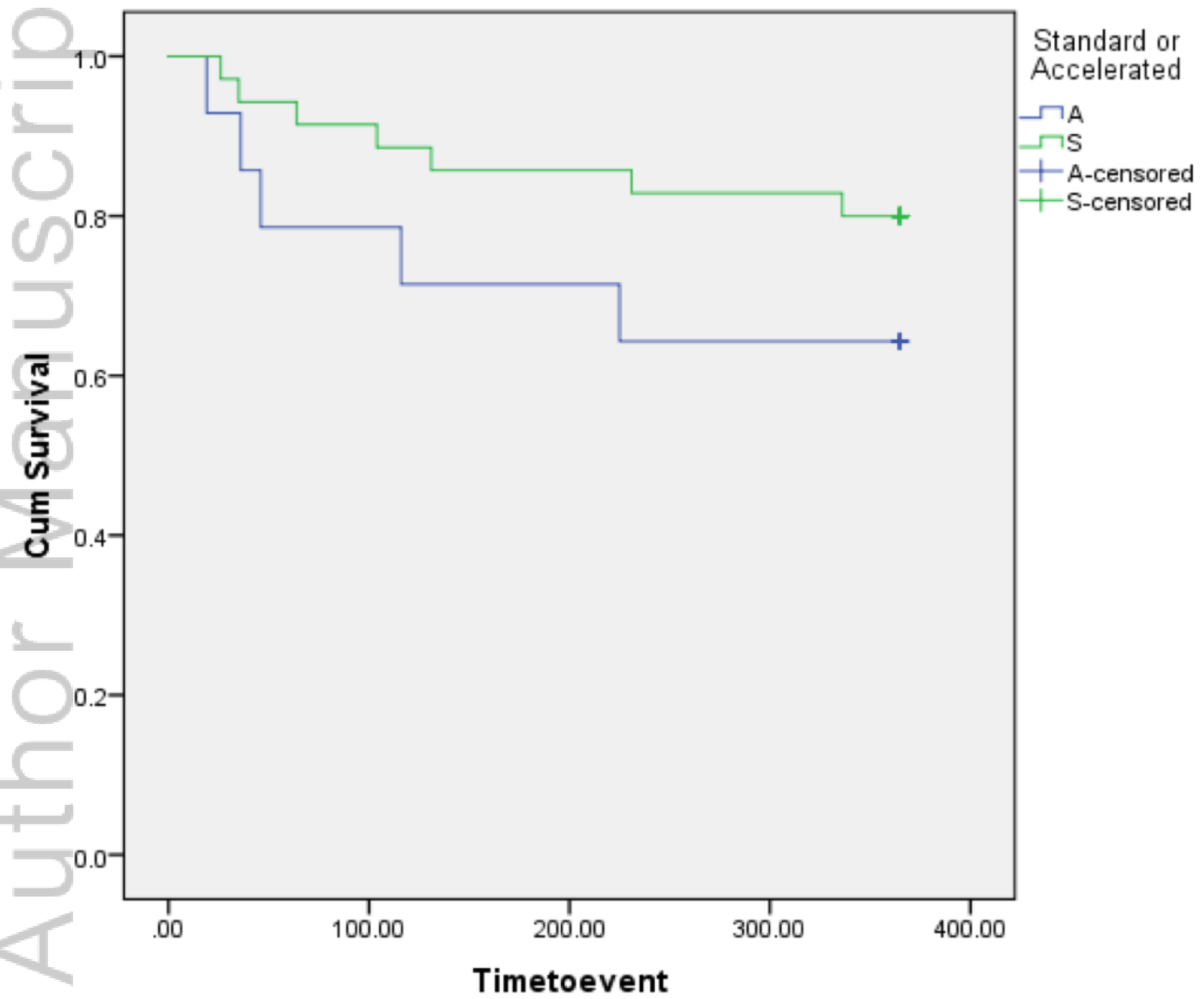

JGH_14072_F2.tiff 


\section{University Library}

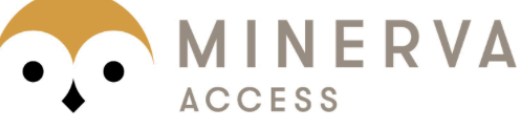

A gateway to Melbourne's research publications

Minerva Access is the Institutional Repository of The University of Melbourne

Author/s:

Choy, MC;Seah, D;Gorelik, A;An, Y-K;Chen, C-Y;Macrae, FA;Sparrow, MP;Connell, WR;Moore, GT;Radford-Smith, G;Van Langenberg, DR;De Cruz, P

Title:

Predicting response after infliximab salvage in acute severe ulcerative colitis

Date:

2018-07-01

\section{Citation:}

Choy, M. C., Seah, D., Gorelik, A., An, Y. -K., Chen, C. -Y., Macrae, F. A., Sparrow, M. P., Connell, W. R., Moore, G. T., Radford-Smith, G., Van Langenberg, D. R. \& De Cruz, P. (2018). Predicting response after infliximab salvage in acute severe ulcerative colitis. JOURNAL OF GASTROENTEROLOGY AND HEPATOLOGY, 33 (7), pp.1347-1352. https:// doi.org/10.1111/jgh.14072.

Persistent Link:

http://hdl.handle.net/11343/283458 